\title{
Formation of aluminum nitride from metal-organic precursors synthesized by reacting aluminum tri-chloride with bis(trimethylsilyl)carbodiimide
}

\author{
Yohei SHIMOKAWA, Akikazu FUJIWARA, Emanuel IONESCU, ${ }^{*}$ Gabriela MERA, ${ }^{*}$ \\ Sawao HONDA, Yuji IWAMOTO ${ }^{\dagger}$ and Ralf RIEDEL* \\ Department of Frontier Materials, Graduate School of Engineering, Nagoya Institute of Technology (NITech), \\ Gokiso-cho, Showa-ku, Nagoya 466-8555, Japan \\ *Disperse Feststoffe, Isnstitut für Materialwissenschaft, Technische Universität Darmstadt (TUD), \\ Jovanka-Bontschits-Straße 2, D-64287 Darmstadt, Deutschland, Germany
}

\begin{abstract}
Metal-organic precursor for aluminum nitride ( $\mathrm{AIN}$ ) ceramics was synthesized by reacting aluminum tri-chloride $\left(\mathrm{AlCl}_{3}\right)$ with bis(trimethylsilyl)carbodiimide (BTSC). Fourier transform infra-red (FT-IR) spectrum of the synthesized precursor exhibited characteristic absorption bands assigned to the carbodiimide $(N=C=N)$ group at $2150-2250$, and $851 \mathrm{~cm}^{-1}$, while the solid state ${ }^{27} \mathrm{Al}$ magic angle spinning nuclear magnetic resonance (MAS NMR) spectrum of the precursor exhibited single signal at $103 \mathrm{ppm}$ which was thought to correspond to $\mathrm{Al}(\mathrm{N}=\mathrm{C}=\mathrm{N})_{4}$ unit. To examine the potential as a precursor for AlN ceramics, the intrinsic thermal conversion behavior up to $1^{\circ 00} \mathrm{C}$ of the synthesized precursor was investigated under argon atmosphere. $\mathrm{X}$-ray diffraction analysis revealed that the crystallization of AIN was found to start above $800^{\circ} \mathrm{C}$, and fully crystallized AIN ceramics was synthesized by the additional heat treatment at $1800^{\circ} \mathrm{C}$. In addition to the FT-IR and NMR spectroscopic analyses for studying the synthetic parameters such as reaction temperature and use of catalyst for the formation of polymeric precursors derived from $\mathrm{AlCl}_{3}$ and $\mathrm{BTSC}$, the effects of heat treatment condition on the polymer/ceramics conversion yield, impurity and crystallinity of the AIN ceramics have been studied by using a thermogravimetric analyzer coupled with a quadrupole mass spectrometer (TG-MS). The results were discussed from a viewpoint to develop a novel synthesis method for AIN ceramics through the polymer precursor route.
\end{abstract}

(02015 The Ceramic Society of Japan. All rights reserved.

Key-words : Aluminum nitride, Polymer-derived ceramics, Metal-organic precursor, Carbodiimide

[Received November 21, 2014; Accepted December 17, 2014]

\section{Introduction}

Aluminum nitride (AlN) ceramics have received considerable attention for their applications such as insulating substrates, heat sinks and host materials for phosphors due to their properties such as high thermal conductivity, high electrical resistivity, low thermal expansion, low dielectric constant, and wide bandgap. ${ }^{1-19)}$ There are two crystalline structures in AlN, hexagonal wurztite and cubic zincblend. The wurztite structure is stable, while the zincblende structure is metastable. ${ }^{20)}$ At present, AlN powders are produced via direct nitridation of aluminum metal, carbothermal reduction (CR) and gas-reduction nitridation (GRN) of alumina $\left(\mathrm{Al}_{2} \mathrm{O}_{3}\right){ }^{21)-27)}$ Direct nitridation usually requires intermediate grinding between successive heat treatments to ensure complete conversion, which allows the possibility of introducing impurities. Reaction times are on the order of hours. In the CR of $\mathrm{Al}_{2} \mathrm{O}_{3}$, controlled oxidation is required to remove unreacted carbon following the reduction, and then vacuum heating must follow, to remove any oxygen. The starting materials are more expensive than those for direct nitridation. ${ }^{7)}$ Moreover, the AlN synthesized by the GRN of $\mathrm{Al}_{2} \mathrm{O}_{3}$ exhibits high oxygen content which affecting the material properties. ${ }^{27)}$ In this study for AlN synthesis, we have focused on the metal-organic precursor/ ceramics conversion route which having potential advantages

Corresponding author: Y. Iwamoto; E-mail: iwamoto.yuji@ nitech. ac.jp compared with the conventional powder synthesis methods: lower processing temperatures in the synthesis of non-oxide covalent ceramics, control of the purity and compositional homogeneity in the final ceramics. ${ }^{28)}$ In the previous studies for AlN synthesis through the metal-organic precursor route, the product prepared by reacting $\mathrm{Me}_{3} \mathrm{Al}\left(\mathrm{Me}=\mathrm{CH}_{3}\right)$ with ammonia was converted into AlN upon pyrolysis. ${ }^{29)}$ AlN was also obtained by pyrolysis of polymeric iminoalane derivatives such as $(\mathrm{HAlNH})_{\mathrm{n}},(\mathrm{RAlNH})_{\mathrm{n}}$, and $(\mathrm{HAlNR})_{\mathrm{n}}\left(\mathrm{R}=\mathrm{Me}\right.$, etc.). ${ }^{29)}$ Additionally, the pyrolysis of the residue synthesized from aluminum tri-chloride $\left(\mathrm{AlCl}_{3}\right)$ and hexamethyldisilazane [HMDS, $\mathrm{HN}\left(\mathrm{SiMe}_{3}\right)_{2}$ ] gave AlN crystallites under $\mathrm{Ar}$ or $\mathrm{NH}_{3}$ atmosphere. ${ }^{30)}$ The detailed reaction scheme is as follows: A reaction between $\mathrm{AlCl}_{3}$ and HMDS occurred at $60^{\circ} \mathrm{C}$ to form $1 / 2\left[\mathrm{Cl}_{2} \mathrm{AlNHSiMe}_{3}\right]_{2}$ with the simultaneous loss of one mole of $\mathrm{Me}_{3} \mathrm{SiCl}$. Thermolysis at $200^{\circ} \mathrm{C}$ of the reaction product led to forming polymeric $(\mathrm{ClAlNH})_{\mathrm{n}}$. Further pyrolysis of the polymer gave AlN crystallites $\left(\mathrm{T} \geqq 500^{\circ} \mathrm{C}\right)$. Furthermore, it is reported that the reaction of $\mathrm{AlCl}_{3}$ with bis(trimethylsilyl)carbodiimide (BTSC) yielded $\mathrm{Cl}_{2} \mathrm{AlNCNSiMe}_{3}[\mathrm{Eq} .(1)]^{31)}$ and $\mathrm{Cl}_{2} \mathrm{AlNCNAl}(\mathrm{Cl}) \mathrm{NCNSi}(\mathrm{Me})_{3}$ [Eq. (2)]. $\left.{ }^{32}\right)$

$$
\begin{aligned}
& \mathrm{AlCl}_{3}+\mathrm{Me}_{3} \mathrm{Si}-\mathrm{N}=\mathrm{C}=\mathrm{N}-\mathrm{SiMe}_{3} \\
& \quad \rightarrow \mathrm{Cl}_{2} \mathrm{AlNCNSiMe}_{3}+\mathrm{Me}_{3} \mathrm{SiCl} \\
& 2 \mathrm{Cl}_{2} \mathrm{AlNCNSiMe}_{3} \\
& \quad \rightarrow \mathrm{Cl}_{2} \mathrm{AlNCNAl}(\mathrm{Cl}) \mathrm{NCNSiMe}_{3}+\mathrm{Me}_{3} \mathrm{SiCl}
\end{aligned}
$$

However, a subsequent reaction of these reactants i.e., further polymerization, cross-linking and conversion into AlN ceramics 
have not studied yet. In particular, the products derived from $\mathrm{AlCl}_{3}$ and $\mathrm{BTSC}$ can be expected to show a polymerization in analogy to the previously reported synthesis of silicon carbodiimide polymers by the reaction of tetrachlorosilane $\left(\mathrm{SiCl}_{4}\right)$ and BTSC with a catalytic amount of pyridine [Eq. (3)]. . $^{33), 34)}$

$$
\begin{aligned}
& n \mathrm{SiCl}_{4}+2 n \mathrm{Me}_{3} \mathrm{Si}-\mathrm{N}=\mathrm{C}=\mathrm{N}-\mathrm{SiMe}_{3} \\
& \stackrel{\text { Pyridine }}{\longrightarrow}\left[\mathrm{Si}(\mathrm{N}=\mathrm{C}=\mathrm{N})_{2}\right]_{n}+4 n \mathrm{Me}_{3} \mathrm{SiCl}
\end{aligned}
$$

If the reaction of $\mathrm{AlCl}_{3}$ and $\mathrm{BTSC}$ can be controlled to yield analogous polymeric product like $\left[\mathrm{Al}(\mathrm{N}=\mathrm{C}=\mathrm{N})_{1.5}\right]_{n}$, the resulting polymer will be useful as a novel meta-organic precursor for AlN ceramics. In this study, the chemical synthesis of metalorganic precursors for AlN ceramics by reacting $\mathrm{AlCl}_{3}$ with BTSC, and thermal conversion of the synthesized precursors into AlN ceramics are investigated.

\section{Experimental procedure}

\subsection{Precursor synthesis}

All experiments were performed under pure and dried $\mathrm{Ar}$ atmosphere using Schlenk and glove box techniques. AlN precursor was synthesized by reacting $\mathrm{AlCl}_{3}$ with $\mathrm{BTSC}$ according to the stoichiometry calculated by the following ideal reaction.

$$
\begin{array}{r}
n \mathrm{AlCl}_{3}+1.5 n \mathrm{Me}_{3} \mathrm{Si}-\mathrm{N}=\mathrm{C}=\mathrm{N}-\mathrm{SiMe}_{3} \\
\rightarrow\left[\mathrm{Al}(\mathrm{N}=\mathrm{C}=\mathrm{N})_{1.5}\right]_{n}+3 n \mathrm{Me}_{3} \mathrm{SiCl}
\end{array}
$$

BTSC was prepared from dicyandiamide (99\%, Kishida Chemical Co., Ltd., Osaka, Japan) and hexamethyldisilazane (96\%, Tokyo chemical Industry Co., Ltd., Tokyo, Japan) with ammonium sulfate $(99.5 \%$, Kishida Chemical Co., Ltd.) as a catalyst according to the literature procedure. ${ }^{35)}$

The BTSC $(7.0 \mathrm{ml}, 0.03 \mathrm{~mol})$ was added dropwise to a stirred $2.7 \mathrm{~g}(0.02 \mathrm{~mol})$ of $\mathrm{AlCl}_{3}$ (99.99\%, Sigma-Aldrich Japan, Tokyo, Japan) in a $300 \mathrm{~mL}$ Schlenk flask. The reaction mixture was stirred at room temperature for $1 \mathrm{~h}$. Then, under vacuum at $60^{\circ} \mathrm{C}$, the liquid byproduct $\left(\mathrm{Me}_{3} \mathrm{SiCl}\right)$ was distilled off, and the reaction product was isolated as highly viscous transparent liquid.

To enhance the polymerization of the reaction product, the effect of pyridine catalyst was studied. A catalytic amount of pyridine $[0.89 \mathrm{ml}(0.011 \mathrm{~mol}), 99.5 \%$, Wako Pure Chemical Industries, Ltd., Osaka, Japan] was added to the reaction mixture, then, the mixture was stirred at room temperature for $1 \mathrm{~h}$. After the distillation of the byproduct of $\mathrm{Me}_{3} \mathrm{SiCl}$ and pyridine under the same manner mentioned above, the reaction product was obtained as white solid.

The reaction catalyzed by pyridine was also performed at $145^{\circ} \mathrm{C}$ by refluxing xylene used as a reaction solvent. All the chemicals mentioned above were dissolved into $5.5 \mathrm{ml}$ of anhydrous xylene (Wako Pure Chemical Industries, Ltd.) at room temperature, then maintained at $145^{\circ} \mathrm{C}$ for $1 \mathrm{~h}$. After the removal of $\mathrm{Me}_{3} \mathrm{SiCl}$, pyridine and xylene, the reaction product was obtained as white solid.

\subsection{Pyrolysis}

The synthesized precursors were pyrolyzed in a quartz tube furnace (ARF60-150-31KC, Asahi Rika Seisakusho Co., Ltd., Chiba, Japan) at temperatures of $200,400,600,800,1000^{\circ} \mathrm{C}$ under flowing Ar. All the samples were heated at a rate of $300^{\circ} \mathrm{C} / \mathrm{h}$ to the desired temperature, held at temperature for $1 \mathrm{~h}$, cooled to room temperature at the same heating rate.

\subsection{Additional heat treatment}

The $800^{\circ} \mathrm{C}$ - and $1000^{\circ} \mathrm{C}$-pyrolyzed samples were ground to a fine powder using an agate mortar and pestle in a glove box. The powdered samples were heat-treated in a graphite resistanceheated furnace (High Multi 5000, Fujidenpa kogyo, Osaka, Japan) under vacuum from room temperature to $1400^{\circ} \mathrm{C}$. Then, $\mathrm{Ar}$ gas was introduced into the furnace at $1400^{\circ} \mathrm{C}$ and the temperature was increased to $1800^{\circ} \mathrm{C}$ with $1 \mathrm{~h}$ holding time under $\mathrm{Ar}$ atmosphere. The heating rate was $600^{\circ} \mathrm{C} / \mathrm{h}$. After the heat treatment, the samples were cooled down to room temperature in a furnace.

\subsection{Characterization}

Fourier transform infra-red (FT-IR) spectra were recorded using Attenuated Total Reflection (ATR) on a FT/IR-4200IF (JASCO Corporation, Tokyo, Japan) with a spectral resolution of $4.0 \mathrm{~cm}^{-1}$.

Solid state ${ }^{27} \mathrm{Al}$ solid-state magic angle spinning (MAS) NMR spectra were measured on Varian UNITY Inova 400 plus (Varian, Palo Alto, California, USA), operating at $60 \mathrm{kHz}$ for Al. The preparation of the samples was done under Ar atmosphere in order to avoid the hydrolysis reaction.

The thermal behavior of the synthesized precursors up to $1400^{\circ} \mathrm{C}$ was studied by means of TGA/MS with a simultaneous thermal analysis device coupled with a quadrupole mass spectrometer (STA 449 Jupiter ${ }^{\circledR}$, Netzsch Japan, Kanagawa, Japan). The measurements were performed under flowing helium with a heating rate of $20^{\circ} \mathrm{C} / \mathrm{min}$.

To investigate the effect of precursor synthesis temperature on the ceramic yield, the weight loss during pyrolysis under $\mathrm{Ar}$ atmosphere was measured by using a conventional thermogravimetric analyzer (TG 8120, Rigaku Corporation, Tokyo, Japan) at a heating rate of $5^{\circ} \mathrm{C} / \mathrm{min}$.

$\mathrm{X}$-ray diffraction (XRD) measurements of the pyrolyzed samples were performed at room temperature using $\mathrm{Cu} K \alpha$ radiation (X'pert Pro $\alpha 1$, Philips, Amsterdam, The Netherlands). The samples were placed in holders filled with $\mathrm{Ar}$ in order to avoid contact with air. XRD analyses of the final product, $1800^{\circ} \mathrm{C}$ heat treated samples were conducted by using a conventional sample holder $(\mathrm{Cu} K \alpha$ radiation, X'pert, Philips, Amsterdam, The Netherlands) at room temperature.

Elemental analyses were performed on $1000^{\circ} \mathrm{C}$-pyrolyzed and $1800^{\circ} \mathrm{C}$-heat treated samples for silicon and aluminum (inductively coupled plasma atomic emission spectroscopy), oxygen and nitrogen (inert-gas fusion method, Model EMGA-930, HORIBA, Ltd., Kyoto, Japan), and carbon (non dispersive infrared method). The chlorine content of the $1000^{\circ} \mathrm{C}$-pyrolyzed sample was determined by the ion chromatography method.

Microstructure of the $1800^{\circ} \mathrm{C}$-heat treated samples was observed by using a scanning electron microscope (SEM, JSM6360LVS, JEOL Ltd., Tokyo, Japan).

\section{Results and discussion}

\subsection{Synthesis of metal-organic precursors and their conversion into AIN ceramics up to $1000^{\circ} \mathrm{C}$}

The reaction of $\mathrm{AlCl}_{3}$ with $\mathrm{BTSC}$ at room temperature gave a viscous liquid product. As shown in Fig. 1(a), the product exhibited IR absorption bands at 2150-2250, 1260 and 851 $\mathrm{cm}^{-1}$ assigned to $\nu(\mathrm{N}=\mathrm{C}=\mathrm{N}), v\left(\mathrm{Si}-\mathrm{CH}_{3}\right)$ and $\delta(\mathrm{N}=\mathrm{C}=\mathrm{N})$ of $\mathrm{Si}-\mathrm{N}=\mathrm{C}=\mathrm{N}$, respectively. ${ }^{33), 34)}$ Another absorption band at $808 \mathrm{~cm}^{-1}$ was thought to correspond to $\delta(\mathrm{N}=\mathrm{C}=\mathrm{N})$ vibration of $\mathrm{Al}-\mathrm{N}=\mathrm{C}=\mathrm{N}$ bonds.

In this study, to examine the potential as a precursor for AlN, the intrinsic thermal decomposition behavior of the synthesized precursor was investigated under Ar atmosphere. Figure 2 shows the thermal behavior of the precursor during pyrolysis up to 


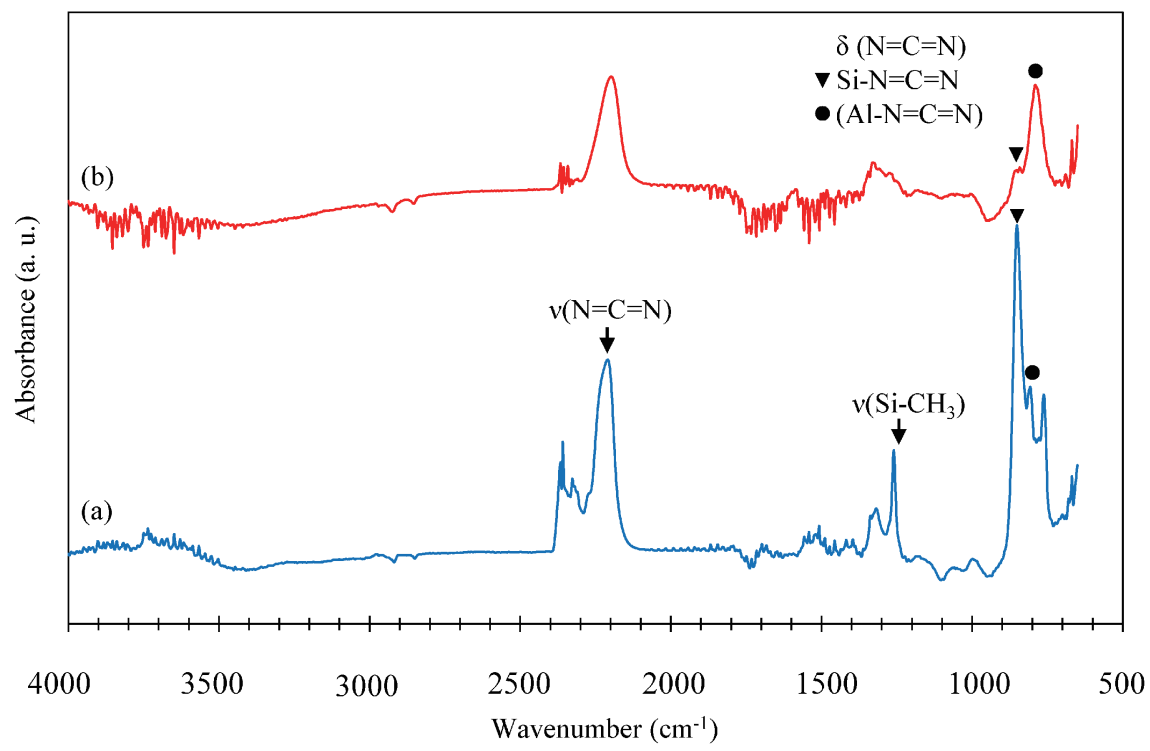

Fig. 1. FT-IR spectra of precursors synthesized by reaction of $\mathrm{AlCl}_{3}$ with $\mathrm{BTSC}$ (a) at room temperature and (b) at room temperature in the presence of a catalytic amount of pyridine.

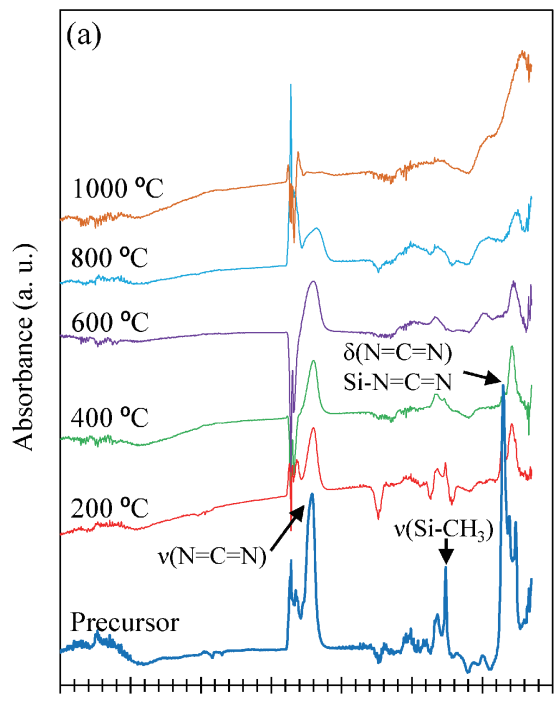

$400035003000250020001500 \quad 1000 \quad 500$ Wavenumber $\left(\mathrm{cm}^{-1}\right)$

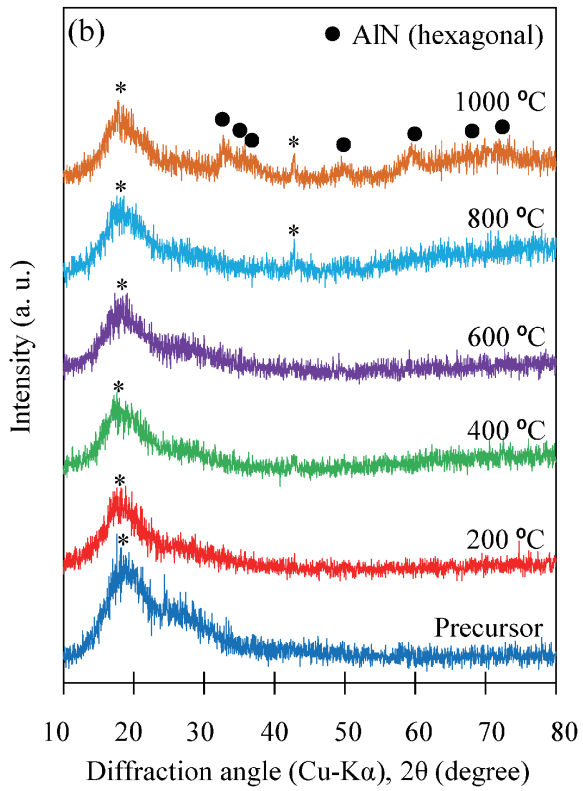

Fig. 2. (a) FT-IR spectra and (b) XRD patterns of precursor synthesized at room temperature and after pyrolysis at temperatures 200 to $1000^{\circ} \mathrm{C}$ under $\mathrm{Ar}$ (The diffraction peaks marked by ${ }^{*}$ were originated from the special sample holder used to avoid contacting with air).

$1000^{\circ} \mathrm{C}$. With increasing the pyrolysis temperature, the IR absorption band due to the carbodiimide group at $2150-2250 \mathrm{~cm}^{-1}$ continuously deceased in intensity, and disappeared after pyrolysis at $1000^{\circ} \mathrm{C}$. The absorption bands due to the $\mathrm{Si}-\mathrm{CH}_{3}(1260$ $\left.\mathrm{cm}^{-1}\right)$ and $\mathrm{Si}-\mathrm{N}=\mathrm{C}=\mathrm{N}\left(851 \mathrm{~cm}^{-1}\right)$ disappeared above $600^{\circ} \mathrm{C}$. On the other hand, the absorption band at $808 \mathrm{~cm}^{-1}$ tuned to be broader and shifted towards lower wavenumber. After pyrolysis at $1000^{\circ} \mathrm{C}$, the sample exhibited one broad band at $716 \mathrm{~cm}^{-1}$ attributed to amorphous or highly distorted AlN (TO phonon mode) ${ }^{36), 37)}$ [Fig. 2(a)].

The XRD patterns of the as-synthesized precursor, and the pyrolyzed samples are shown in Fig. 2(b). The broad diffraction peak at around $2 \theta$ (degrees) of 20 , and the miner peak at $2 \theta$ (degrees) of 43 (marked by ${ }^{*}$ ) were originated from the special sample holder used to avoid contacting with air. The pyrolyzed sample was X-ray amorphous up to $800^{\circ} \mathrm{C}$, then the initial crystallization was found to start above $800^{\circ} \mathrm{C}$, and the $1000^{\circ} \mathrm{C}$ pyrolyzed sample exhibited several diffraction peaks which were identical to those of hexagonal AIN (JCPDS Card No. 025-1133).

The results of FT-IR and XRD analyses reveal that the reaction of $\mathrm{AlCl}_{3}$ with BTSC investigated in this study could follow the previously reported scheme: ${ }^{31), 32)}$ formation of a dimeric compound $\mathrm{Cl}_{2} \mathrm{AlNCNSiMe}$ by the simultaneous loss of one mole of $\mathrm{Me}_{3} \mathrm{SiCl}$ according the Eq. (1), followed by yielding $\mathrm{Cl}_{2} \mathrm{AlNCNAl}(\mathrm{Cl}) \mathrm{NCNSiMe}_{3}$ with the elimination of second mole of $\mathrm{Me}_{3} \mathrm{SiCl}$ as shown in the Eq. (2).

During pyrolysis to $1000^{\circ} \mathrm{C}$, further condensation proceeded with elimination of the $\mathrm{Me}_{3} \mathrm{Si}-\mathrm{N}=\mathrm{C}=\mathrm{N}$ end groups, which 

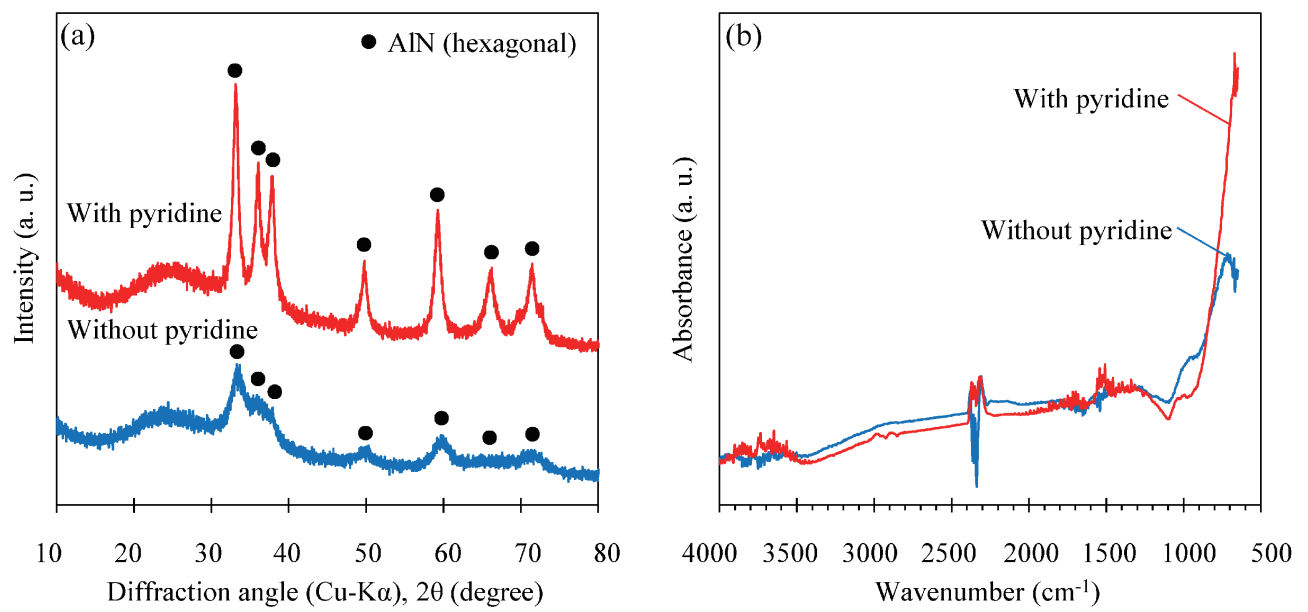

Fig. 3. (a) XRD patterns and (b) FT-IR spectra of $1000^{\circ} \mathrm{C}$-pyrolyzed samples showing enhancement of AIN crystallization by use of pyridine catalyst in the chemical synthesis of precursors.

seemed to form the ideal polycarbodiimide derivative, $\left[\mathrm{Al}(\mathrm{N}=\mathrm{C}=\mathrm{N})_{1.5}\right]_{n}$ as shown in the Eq. (4). However, the ceramic yield up to $1000^{\circ} \mathrm{C}$ was below $10 \%$. Then, to increase the yield by enhancing the further condensation reaction during the chemical synthesis of the metal-organic precursor, the reaction of $\mathrm{AlCl}_{3}$ with BTSC was conducted in the presence of a catalytic amount of pyridine. ${ }^{33), 34)}$ After the reaction for $1 \mathrm{~h}$, the reaction mixture was maintained under vacuum at $60^{\circ} \mathrm{C}$, and the byproduct of $\mathrm{Me}_{3} \mathrm{SiCl}$ and the pyridine were distilled off. Then, the reaction product was isolated as white solid.

Compared with Fig. 1(a), in the IR spectrum of the solid product [Fig. 1(b)], the absorption band due to the $\mathrm{Si}-\mathrm{CH}_{3}$ $\left(1260 \mathrm{~cm}^{-1}\right)$ almost disappeared. The band intensity of the Si$\mathrm{N}=\mathrm{C}=\mathrm{N}\left(851 \mathrm{~cm}^{-1}\right)$ apparently decreased, while the absorption band at $808 \mathrm{~cm}^{-1}$ showed remarkable increase in intensity, and slightly shifted to $791 \mathrm{~cm}^{-1}$.

Figure 3 shows (a) XRD patterns and (b) FT-IR spectra of the $1000^{\circ} \mathrm{C}$-pyrolyzed samples derived from the metal-organic precursors synthesized with and without pyridine catalyst. For the XRD measurements, a normal sample folder was used to examine the degree of crystallization. The peak intensity of the XRD pattern identified as AIN phase apparently increased by the use of pyridine catalyst [Fig. 3(a)]. In addition, the IR absorption band originally located at $716 \mathrm{~cm}^{-1}$ exhibited apparent increase in intensity and sifted to be located at $670 \mathrm{~cm}^{-1}$, closely to that at $667 \mathrm{~cm}^{-1}$ assigned to crystalline AIN (TO phonon mode). ${ }^{36), 37)}$

To investigate the formation of AlN in more details, thermal decomposition behavior of the metal-organic precursor synthesized using pyridine catalyst was in-situ analyzed by using the STA technique. The results are shown in Fig. 4. The sample exhibited main weight loss of approximately $70 \%$ in the temperature range from 100 to $400^{\circ} \mathrm{C}$, and continuous weight loss of $13 \%$ up to $1100^{\circ} \mathrm{C}$ [Fig. 4(A)]. The gaseous products of $\mathrm{C}_{2} \mathrm{~N}_{2}$ and $\mathrm{N}_{2}$ were detected in the two temperature ranges, 100 to $400^{\circ} \mathrm{C}$ and 800 to $1100^{\circ} \mathrm{C}$, while $\mathrm{Me}_{3} \mathrm{SiCl}$ was detected in the first temperature range of 100 to $400^{\circ} \mathrm{C}$. Another silicon containing product, $\mathrm{MeSiH}_{3}$ was also detected mainly at 100 to $400^{\circ} \mathrm{C}$, then continuously detected up to $1100^{\circ} \mathrm{C}$. Other gaseous products identified were a trace amount of residual pyridine (not shown), and $\mathrm{HCl}$ detected in the two temperature ranges, 100 to $400^{\circ} \mathrm{C}$ and 600 to $1100^{\circ} \mathrm{C}$ [Fig. 4(B)].

Figure 5 presents a solid state ${ }^{27} \mathrm{Al}$ MAS NMR spectrum of the $1000^{\circ} \mathrm{C}$-pyrolyzed sample derived from the metal-organic

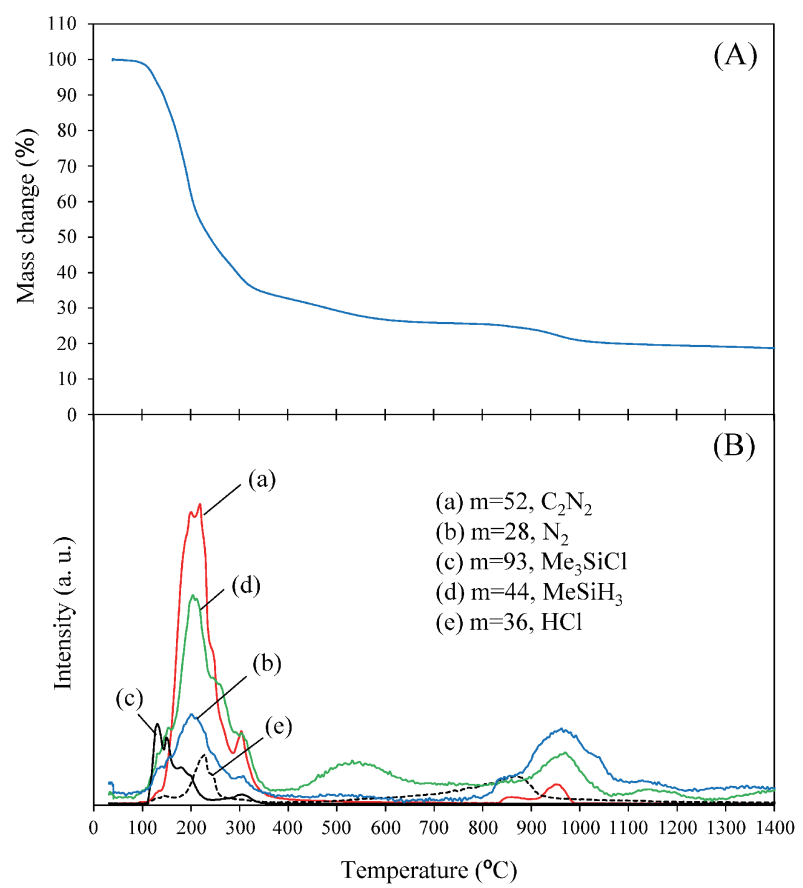

Fig. 4. (A) Thermogravimetric analysis of AlN precursor synthesized using pyridine catalyst, as well as (B) the monitoring of the pyrolysis under helium by mass spectrometry of the gaseous $\mathrm{C}_{2} \mathrm{~N}_{2}, \mathrm{~N}_{2}, \mathrm{Me}_{3} \mathrm{SiCl}$, $\mathrm{MeSiH}_{3}$ and $\mathrm{HCl}$ from the polymeric precursor synthesized using pyridine catalyst.

precursor synthesized using pyridine catalyst, and those of assynthesized precursor, reagent grade of commercial AlN and starting compound of $\mathrm{AlCl}_{3}$. The as-synthesized precursor exhibits single signal at $103 \mathrm{ppm}$ which apparently sifted towards lower field from that of $\mathrm{AlCl}_{3}(-0.73 \mathrm{ppm})$. Taking into account of the results obtained by the FT-IR analysis, this signal was thought to attribute to tetrahedral $\mathrm{Al}(\mathrm{N}=\mathrm{C}=\mathrm{N})_{4}$ $\left[-\mathrm{N}=\mathrm{C}=\mathrm{N} \rightarrow \mathrm{Al}(\mathrm{N}=\mathrm{C}=\mathrm{N})_{3}\right]$ unit. After pyrolysis at $1000^{\circ} \mathrm{C}$, the signal was further sifted to $113 \mathrm{ppm}$, and well consistent with that of AlN assigned to tetrahedral $\left[=\mathrm{N} \rightarrow \mathrm{Al}(\mathrm{N}=)_{3}\right]\left(\mathrm{AlN}_{4}\right)$ unit. ${ }^{38), 39)}$

Table 1 summarizes the result of elemental analysis performed on the $1000^{\circ} \mathrm{C}$-pyrolyzed sample derived from the polymeric 
precursor synthesized using pyridine catalyst, and the literature data reported for the $1000^{\circ} \mathrm{C}$ - and $1300^{\circ} \mathrm{C}$-pyrolyzed samples derived from $\mathrm{AlCl}_{3}$ and $\mathrm{HMDS}^{30)}$ Both $\mathrm{Cl}$ and $\mathrm{Si}$ impurities in this study were much lower than those of the literature data, however, the resulting ceramic yield was $20 \%$. This value was much lower than the theoretical one (47\%) calculated according to the following ideal reaction.

$$
\left[\mathrm{Al}(\mathrm{N}=\mathrm{C}=\mathrm{N})_{1.5}\right]_{n} \stackrel{\text { Pyrolysis }}{\longrightarrow} n \mathrm{AlN}+3 / 4 n \mathrm{C}_{2} \mathrm{~N}_{2}+1 / 4 n \mathrm{~N}_{2}
$$

Moreover, the $1000^{\circ} \mathrm{C}$-pyrolyzed sample in this study contained relatively higher amount of oxygen $(5.94 \mathrm{wt} \%)$ and carbon $(12.2 \mathrm{wt} \%)$. The $1000^{\circ} \mathrm{C}$-pyrolyzed sample was thought to be highly reactive towards ambient moisture, and most of the measured oxygen could be accumulated during the sample loading and transfer steps in the analysis. On the other hand, the relatively higher amount of carbon revealed that the thermal decomposition of $\mathrm{N}=\mathrm{C}=\mathrm{N}$ groups yielded considerable amount of free carbon together with gaseous $\mathrm{C}_{2} \mathrm{~N}_{2}$ and $\mathrm{N}_{2}$. Furthermore, the sum of the composition calculated for the $1000^{\circ} \mathrm{C}$-pyrolyzed sample was $92.58 \%$, which suggesting approximately $7 \%$ of unknown residue.

The proposed polymeric structure of the metal-organic precursor, and the precursor/AIN ceramics conversion behavior investigated in this study are depicted in Fig. 6. The reaction of $\mathrm{AlCl}_{3}$ with BTSC was successfully catalyzed by pyridine to yield polymeric product composed of tetrahedral

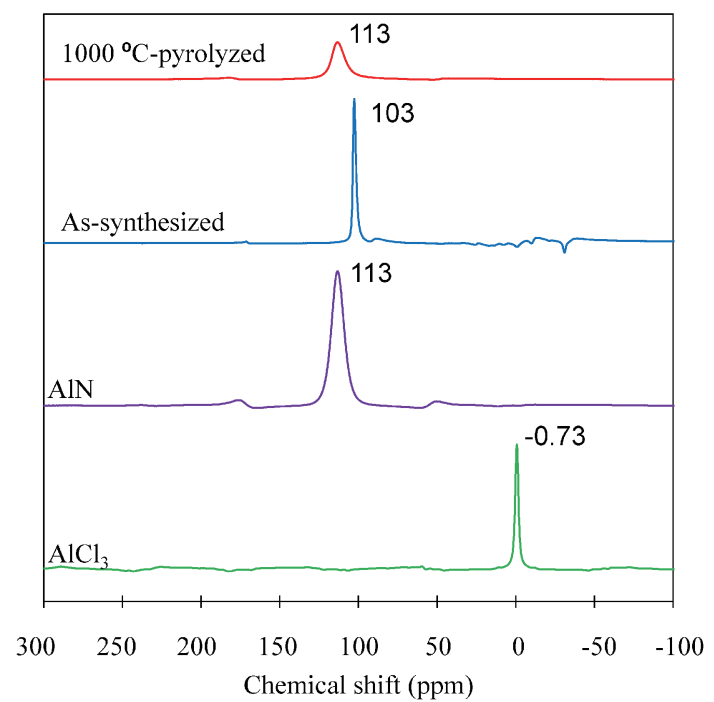

Fig. 5. Solid state ${ }^{27} \mathrm{Al}$ MAS NMR spectra of $1000^{\circ} \mathrm{C}$-pyrolyzed sample, AlN precursor synthesized using pyridine catalyst, reagent grade of commercial AlN and starting compound of $\mathrm{AlCl}_{3}$.
$\left[-\mathrm{N}=\mathrm{C}=\mathrm{N} \rightarrow \mathrm{Al}(\mathrm{N}=\mathrm{C}=\mathrm{N})_{3}\right]$ unit. The $\mathrm{Me}_{3} \mathrm{SiCl}$ detected at 100 to $400^{\circ} \mathrm{C}$ was the by-product [shown in Eq. (4)] physically trapped within the polymeric product. However, the detection of the $\mathrm{MeSiH}_{3}$ by the TG-MS analysis revealed the existence of the $-\mathrm{N}=\mathrm{C}=\mathrm{N}-\mathrm{SiMe}_{3}$ end groups, and a certain amount of the unreacted BTSC which could be also physically trapped in the polymeric product. Since aluminum species were not detected, the $\mathrm{AlCl}_{3}$ remained and the $-\mathrm{N}=\mathrm{C}=\mathrm{N}-\mathrm{SiMe}_{3}$ end groups, and/or some of the residual $\mathrm{BTSC}$ could yield $\mathrm{Me}_{3} \mathrm{SiCl}$ and unidentified compounds during the pyrolysis.

Taking into account of the results obtained by the XRD and FT-IR analyses shown in Fig. 2, decomposition of the $\mathrm{N}=\mathrm{C}=\mathrm{N}$ groups to yield gaseous $\mathrm{C}_{2} \mathrm{~N}_{2}$ and $\mathrm{N}_{2}$ at $100-400^{\circ} \mathrm{C}$ promoted conversion of the metal-organic polymer into inorganic amorphous Al-N-C having small amount of the residual $\mathrm{N}=\mathrm{C}=\mathrm{N}$ groups. At and above $800^{\circ} \mathrm{C}$, the decomposition of the residual

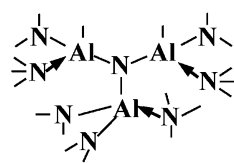

Crystalline AIN

$$
\mathrm{AlN}_{4} \text { unit }
$$

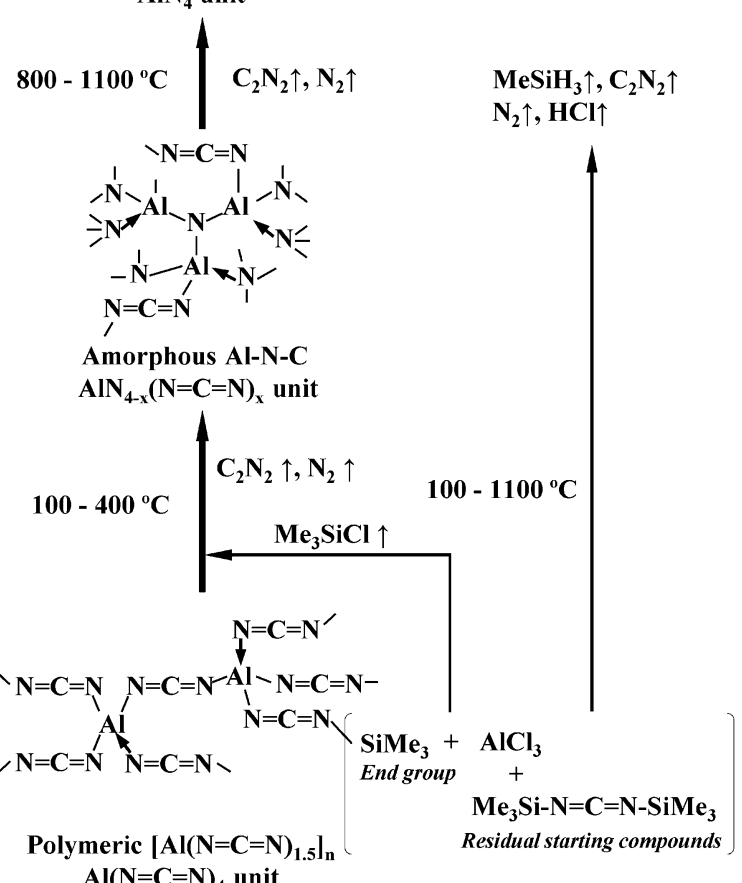

Fig. 6. Proposed polymeric structure of the metal-organic precursor, and the precursor/AlN ceramics conversion behavior investigated in this study.

Table 1. The result of elemental analysis performed on the $1000^{\circ} \mathrm{C}$-pyrolyzed sample derived from the precursor synthesized using pyridine catalyst, and

\begin{tabular}{|c|c|c|c|c|c|c|c|c|c|}
\hline \multirow{2}{*}{\multicolumn{2}{|c|}{$\begin{array}{l}\text { Heat Treatment } \\
\text { Temp. }\left({ }^{\circ} \mathrm{C}\right) \text { in } \mathrm{Ar}\end{array}$}} & \multirow{3}{*}{$\begin{array}{c}\text { Holding Time } \\
\text { (h) }\end{array}$} & \multicolumn{6}{|c|}{ Composition (wt \%) } & \multirow{3}{*}{$\begin{array}{r}\text { Starting } \\
\text { Material } \\
{ }^{*} \text { BTSC }\end{array}$} \\
\hline & & & \multirow{2}{*}{$\begin{array}{c}\mathrm{N} \\
22.9\end{array}$} & \multirow{2}{*}{$\begin{array}{c}\mathrm{O} \\
5.94\end{array}$} & \multirow{2}{*}{$\begin{array}{c}\mathrm{Cl} \\
2.9\end{array}$} & \multirow{2}{*}{$\begin{array}{c}\mathrm{Al} \\
48.6\end{array}$} & \multirow{2}{*}{$\begin{array}{c}\mathrm{Si} \\
0.044\end{array}$} & \multirow{2}{*}{$\begin{array}{c}\mathrm{C} \\
12.2\end{array}$} & \\
\hline This study & 1000 & & & & & & & & \\
\hline \multirow[t]{2}{*}{ Lit. $^{30)}$} & 1000 & 1 & 26.7 & 6.4 & 14 & - & - & - & ${ }^{+} \mathrm{HMDS}$ \\
\hline & 1300 & 7 & 28.3 & 7.6 & $\leqq 0.1$ & 54.3 & 7.4 & 0.10 & \\
\hline \multirow{2}{*}{\multicolumn{3}{|c|}{$\begin{array}{l}\text { Aluminum carbodiimide: } \mathrm{Al}(\mathrm{NCN})_{1.5} \\
\text { Aluminum nitride: AlN }\end{array}$}} & 48.3 & - & - & 31.0 & - & 20.7 & \\
\hline & & & 34.1 & - & - & 65.9 & - & - & \\
\hline
\end{tabular}
the literature data reported for the $1000^{\circ} \mathrm{C}$ - and $1300^{\circ} \mathrm{C}$-pyrolyzed samples derived from $\mathrm{AlCl}_{3}$ and $\mathrm{HMDS}^{30}$ )

*BTSC: Bis(trimethylsilyl)carbodiimide, ${ }^{+}$HMDS: Hexamethyldisilazane. 


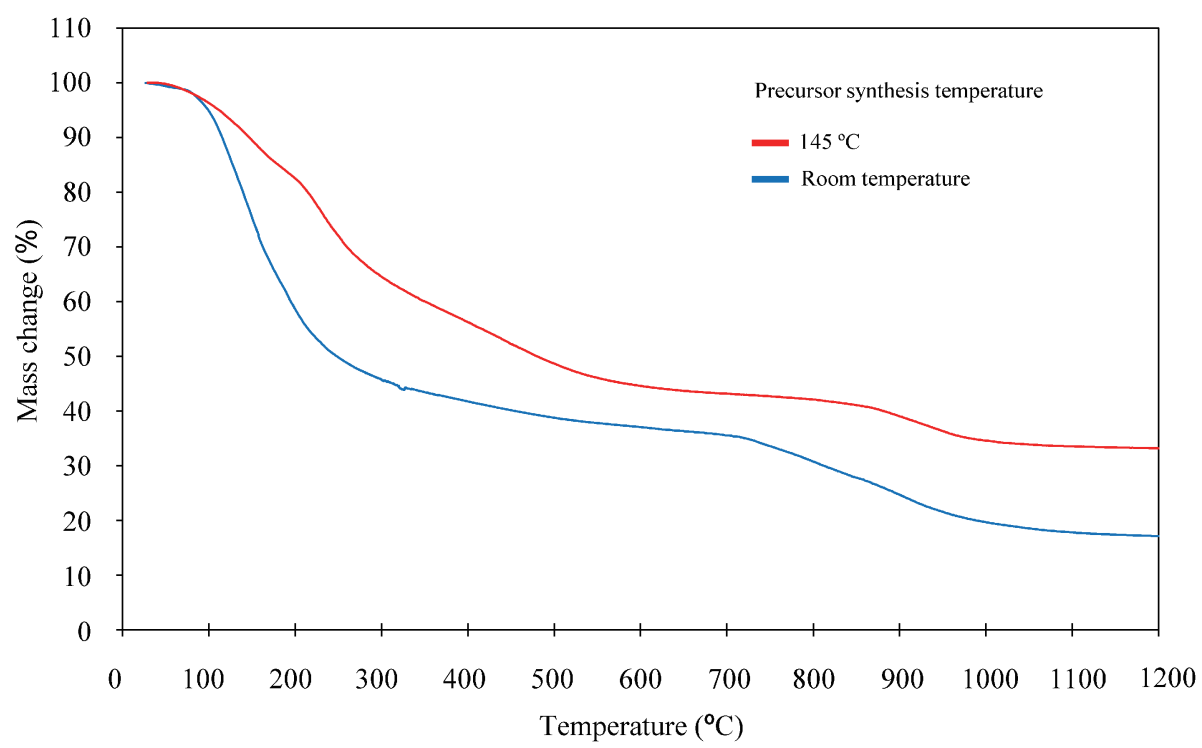

Fig. 7. The mass change in the temperature range between room temperature and $1200^{\circ} \mathrm{C}$ under Ar of the two precursors synthesized at the different temperature in the presence of catalytic amount of pyridine.

$\mathrm{N}=\mathrm{C}=\mathrm{N}$ groups lead to the formation of amorphous Al-N network composed of tetrahedral $\mathrm{AlN}_{4}$ unit and subsequent crystallization of AlN. During the pyrolysis up to $1000^{\circ} \mathrm{C}$, the residual starting compounds decomposed to yield gaseous species which could contribute to improve the purity of AIN to some extent.

\subsection{Improvement of ceramic yield, purity and crystallinity of AIN derived from synthesized precursor}

Based on the results shown above, the following two additional experimental studies were performed for improving the ceramic yield, purity and crystallinity of the precursor-derived AIN: (1) Increasing the precursor synthesis temperature from room temperature to $145^{\circ} \mathrm{C}$ by use of xylene as a reaction solvent. As shown in Fig. 3, the use of pyridine successfully catalyzed to yield polymeric precursor at room temperature, which resulted in enhancing the AlN crystallization at $1000^{\circ} \mathrm{C}$. The increased reaction temperature was thought to enhance further polymerization to form highly cross-linked three-dimensional polymer network, which was expected to improve the ceramic yield and crystallinity of the precursor-derived AIN. (2) Additional heat treatment under vacuum to $1400^{\circ} \mathrm{C}$ and subsequent heat treatment up to $1800^{\circ} \mathrm{C}$ under $\mathrm{Ar}$ atmosphere. In this strategy, the first pyrolysis temperature was decreased to $800^{\circ} \mathrm{C}$ (the onset temperature of the residual $\mathrm{N}=\mathrm{C}=\mathrm{N}$ group decomposition), which was expected to reducing amount of free carbon and improvement of the crystallinity of AIN.

Figure 7 shows the mass change in the temperature range between room temperature and $1200^{\circ} \mathrm{C}$ under $\mathrm{Ar}$ of the two precursors synthesized at the different temperature. Apparently, the weight loss of the precursor due to the decomposition of $\mathrm{N}=\mathrm{C}=\mathrm{N}$ groups in the first temperature range from 100 to $400^{\circ} \mathrm{C}$ was suppressed by increasing the synthesis temperature to $145^{\circ} \mathrm{C}$, and the resulting ceramic yield at $1000^{\circ} \mathrm{C}$ was successfully improved from 20 to $35 \%$.

The results of elemental analysis performed on the $1800^{\circ} \mathrm{C}$ heat treated samples are listed in Table 2. The oxygen and carbon contents were remarkably deceased by the modified pyrolysis and additional heat treatment. The chemical synthesis of precursor at
Table 2. Chemical composition and ceramic yield of the precursorderived AlN after the heat treatment at $1800^{\circ} \mathrm{C}$ for $1 \mathrm{~h}$ in $\mathrm{Ar}$

\begin{tabular}{ccccc}
\hline \multirow{2}{*}{$\begin{array}{c}\text { Precursor synthesis } \\
\text { temperature }\end{array}$} & \multicolumn{3}{c}{ Composition (wt \%) } & \multirow{2}{*}{$\begin{array}{c}\text { Ceramic yield } \\
(\%)\end{array}$} \\
\cline { 2 - 4 } & $\mathrm{N}$ & $\mathrm{O}$ & $\mathrm{C}$ & 9 \\
\hline r.t. & 29.2 & 0.37 & 3.77 & 18 \\
\hline $145^{\circ} \mathrm{C}$ & 32.1 & 0.98 & 1.55 & \\
\hline
\end{tabular}

$145^{\circ} \mathrm{C}$ resulted in further reduction of the free carbon content in the final ceramics (from 3.77 to $1.55 \mathrm{wt} \%$ ). As shown in Figs. 8(a)-8(c), with decreasing the carbon content, the sample color changed from black to gray, then to grayish white. On the other hand, the morphology of the sample apparently changed by the additional heat treatment. The $1000^{\circ} \mathrm{C}$-pyrolyzed sample was composed of irregular shaped particles having a size range of about 0.1 to $2 \mu \mathrm{m}$ [Fig. $8(\mathrm{~d})$ ]. The $1800^{\circ} \mathrm{C}$-heat treated sample derived from the precursor synthesized at room temperature showed a bimodal structure composed of fine grains about 500 $\mathrm{nm}$ in size and coarse grains with a diameter of about $3 \mu \mathrm{m}$ [Fig. 8(e)]. One possible reason for the partial grain growth was thought to be due to the inhomogeneous formation of small amount of liquid phase derived from AIN and relatively higher amount of silicon and oxygen impurities compared with those in the sample derived from the $145^{\circ} \mathrm{C}$-synthesized precursor. On the other hand, the $1800^{\circ} \mathrm{C}$ heat-treated sample derived from the precursor synthesized at $145^{\circ} \mathrm{C}$ exhibited a uniform and finegrained microstructure composed of equiaxed grains having a size rage of approximately 200 to $500 \mathrm{~nm}$ [Fig. 8(f)]. Compared with the $1000^{\circ} \mathrm{C}$-pyrolyzed sample, the AIN diffraction lines of this sample remarkably increased in intensity (Fig. 9). The fully crystallized fine-grained AIN could increase stability against oxidation in air, which contributing to the suppression of the oxygen contamination in the final AIN ceramics.

\section{Conclusions}

Metal-organic compounds were synthesized from $\mathrm{AlCl}_{3}$ and bis(trimethylsilyl)-carbodiimide (BTSC), and to examine the potential as precursors for AIN ceramics, the intrinsic thermal decomposition behavior of the synthesized compounds was 

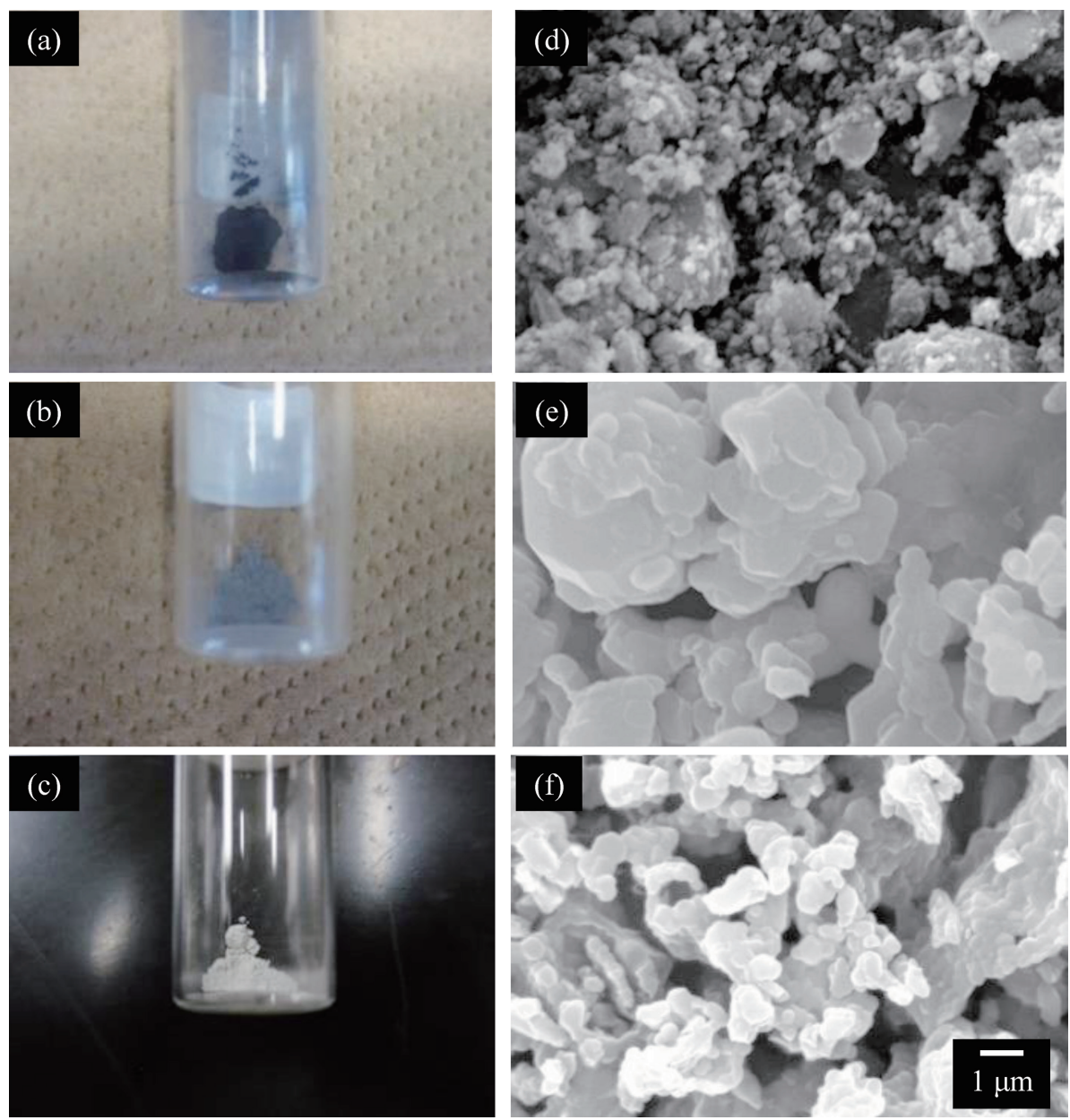

Fig. 8. The color and SEM image of AlN ceramics derived from the precursor synthesized using pyridine catalyst. (a), (d): $1000^{\circ} \mathrm{C}$-pyrolyzed sample derived from the precursor synthesized at room temperature, (b), (e): $1800^{\circ} \mathrm{C}$-heat treated sample derived from the precursor synthesized at room temperature, and (c), (f): $1800^{\circ} \mathrm{C}$-heat treated sample derived from the precursor synthesized at $145^{\circ} \mathrm{C}$

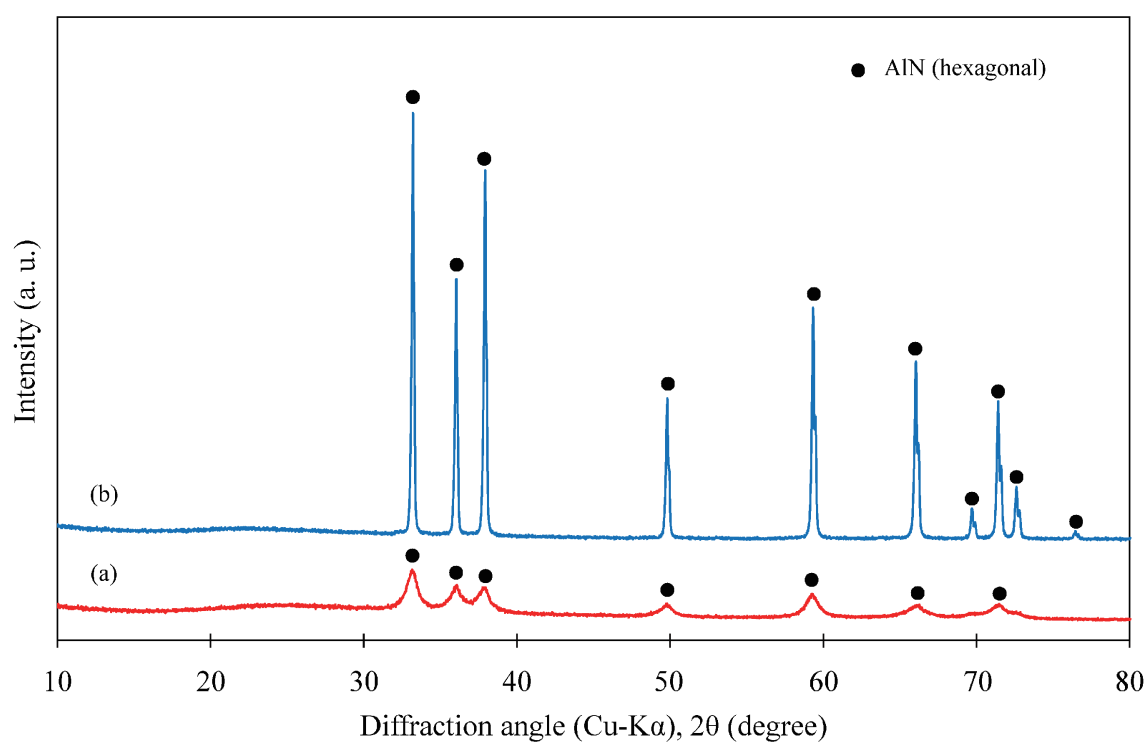

Fig. 9. XRD patterns of precursor-derived AlN ceramics. (a) $1000^{\circ} \mathrm{C}$-pyrolyzed sample derived from the precursor synthesized using pyridine catalyst at room temperature, and (b) $1800^{\circ} \mathrm{C}$-heat treated sample derived from the precursor synthesized at $145^{\circ} \mathrm{C}$ using pyridine catalyst. 
investigated under Ar atmosphere. The results can be summarized as follows:

(1) FT-IR and solid state ${ }^{27} \mathrm{Al}$ MAS NMR spectroscopic analyses revealed that the reaction of $\mathrm{AlCl}_{3}$ with BTSC occurred at room temperature. The use of pyridine as a catalyst and increasing the reaction temperature to $145^{\circ} \mathrm{C}$ resulted in enhancing further condensation of the reaction product to give polymeric compound ideally expressed as $\left[\mathrm{Al}(\mathrm{N}=\mathrm{C}=\mathrm{N})_{1.5}\right]_{n}$.

(2) The pyrolyzed compound kept X-ray amorphous state up to $800^{\circ} \mathrm{C}$, then, exhibited AlN hexagonal crystalline diffraction line after pyrolysis at $1000^{\circ} \mathrm{C}$.

(3) TG-MS analysis revealed that the decomposition of the $\mathrm{N}=\mathrm{C}=\mathrm{N}$ groups at 200 to $400^{\circ} \mathrm{C}$ with evolution of gaseous $\mathrm{N}_{2}$ and $\mathrm{C}_{2} \mathrm{~N}_{2}$ promoted the formation of amorphous Al-N-C having a small amount of the residual $\mathrm{N}=\mathrm{C}=\mathrm{N}$ groups. Further decomposition of the $\mathrm{N}=\mathrm{C}=\mathrm{N}$ groups at and above $800^{\circ} \mathrm{C}$ could lead to the formation of amorphous $\mathrm{Al}-\mathrm{N}$ and subsequent AIN crystallization.

(4) Additional heat treatment up to $1800^{\circ} \mathrm{C}$ was effective to improve the purity, and crystallinity of the precursorderived AlN ceramics

(5) One important synthetic factor in this metal-organic precursor route is formation of uniform and highly crosslinked polymer network of $=\mathrm{Al}-\mathrm{N}=\mathrm{C}=\mathrm{N}-\mathrm{Al}=$ linkage in the chemical synthesis of precursor, which can suppress the carbon impurity and enhance the final ceramic yield after the additional heat treatment up to $1800^{\circ} \mathrm{C}$.

These results suggest that the metal-organic polymer compound investigated in this study has a potential as a novel precursor for synthesizing AIN ceramics with controlled impurity.

Acknowledgments This research work has been carried out as a collaboration research work between NITech and TUD supported by the Strategic Young Researcher Overseas Visits Program for Accelerating Brain Circulation.

\section{References}

1) Y. Kurokawa, K. Utsumi, H. Takamizawa, T. Kamata and S. Noguchi, IEEE Trans. Compon., Hybrids, Manuf. Technol., 8, 247-252 (1985).

2) N. Kuramoto, H. Taniguchi and I. Aso, IEEE Trans. Compon., Hybrids, Manuf. Technol., 9, 386-390 (1986).

3) K. A. Khor, K. H. Cheng, L. G. Yu and F. Boey, Mater. Sci. Eng., A, 347, 300-305 (2003).

4) G. A. Slack, R. A. Tanzilli, R. O. Pohl and J. W. Vandersande, J. Phys. Chem. Solids, 48, 641-647 (1987).

5) R. R. Lee, J. Am. Ceram. Soc., 74, 2242-2249 (1991).

6) Q. Guo, M. Nishio, H. Ogawa and A. Yoshida, Phys. Rev. B, 64, 113105 (2001).

7) S. M. Bradshaw and J. L. Spicer, J. Am. Ceram. Soc., 82, 2293-2300 (1999).

8) W. M. Jadwisienczak, H. J. Lozykowski, I. Berishev, A. Bensaoula and I. G. Brown, J. Appl. Phys., 89, 4384-4390 (2001).

9) B. Dierre, X. L. Yuan, K. Inoue, N. Hirosaki, R. J. Xie and T. Sekiguchi, J. Am. Ceram. Soc., 92, 1272-1275 (2009).

10) K. Inoue, N. Hirosaki, R. J. Xie and T. Takeda, J. Phys. Chem. C, 113, 9392-9397 (2009).
11) H. S. Do, S. W. Choi and S. H. Hong, J. Am. Ceram. Soc., 93, 356-358 (2010).

12) T. Takeda, N. Hirosaki, R. J. Xie, K. Kimoto and M. Saito, J. Mater. Chem., 20, 9948-9953 (2010).

13) L. J. Yin, Q. Q. Zhu, W. Yu, L. Y. Hao, X. Xu, F. C. Hu and M. H. Lee, J. Appl. Phys., 111, 053534 (2012).

14) B. Dierre, X. M. Zhang, N. Fukata, T. Sekiguchi, T. Suehiro, T. Takeda, R. J. Xie and N. Hirosaki, J. Solid State Sci. Technol., 2, R126-R130 (2013).

15) T. Miyajima, Y. Kudo, T. Uruga and K. Hara, Phys. Status Solidi (c), 3, 1742-1745 (2006).

16) H. Zhang, M. Zheng, B. Lei, Y. Liu, Y. Xiao, H. Dong, Y. Zhang and S. Ye, J. Solid State Sci. Technol., 2, R117-R120 (2013).

17) X. J. Wang, R. J. Xie, B. Dierre, T. Takeda, T. Suehiro, N. Hirosaki, T. Sekiguchi, H. Li and Z. Sun, Dalton Trans., 43, 6120-6127 (2014).

18) T. C. Liu, H. Kominami, H. F. Greer, W. Zhou, Y. Nakanishi and R. S. Liu, Chem. Mater., 24, 3486-3492 (2012).

19) R. Ishikawa, A. R. Lupini, F. Oba, S. D. Findlay, N. Shibata, T. Taniguchi, K. Watanabe, H. Hayashi, T. Sakai, I. Tanaka, Y. Ikuhara and S. J. Pennycook, Sci. Rep., 4, 1-5 (2014).

20) I. Petrov, E. Mojab, R. C. Powell, J. E. Greene, L. Hultman and J. E. Sundgren, Appl. Phys. Lett., 60, 2491-2493 (1992).

21) A. W. Weimer, G. A. Cochran, G. A. Eisman, J. P. Henley, B. D. Hook and L. K. Mills, J. Am. Ceram. Soc., 77, 3-18 (1994).

22) A. A. Elagin, A. R. Beketov, M. V. Baranov and R. A. Shishkin, Refract. Ind. Ceram., 53, 395-403 (2013).

23) R. Bachelard and P. Joubert, Mater. Sci. Eng., A, 109, 247-251 (1989).

24) R. G. O'donnell and M. B. Trigg, Micron, 25, 575-579 (1994).

25) H. K. Chen and C. I. Lin, J. Mater. Sci., 29, 1352-1357 (1994).

26) T. Suehiro, J. Tatami, T. Meguro, S. Matsuo and K. Komeya, J. Eur. Ceram. Soc., 22, 521-526 (2002).

27) T. Suehiro, N. Hirosaki, R. Terao, J. Tatami, T. Meguro and K. Komeya, J. Am. Ceram. Soc., 86, 1046-1048 (2003).

28) R. Riedel and W. Dressler, Ceram. Int., 22, 233-239 (1996).

29) Y. Mori and Y. Sugahara, J. Ceram. Soc. Japan, 114, 461-472 (2006).

30) R. Riedel, G. Petzow and U. Klingebiel, J. Mater. Sci. Lett., 9, 222-224 (1990).

31) R. Riedel, E. Kroke, A. Greiner, A. O. Gabriel, L. Ruwisch, J. Nicolich and Peter Kroll, Chem. Mater., 10, 2964-2979 (1998).

32) P. Haag, R. Lechler and J. Weidlein, Z. Anorg. Allg. Chem., 620, 112-116 (1994).

33) R. Riedel, A. Grainer, G. Miehe, W. Dressler, H. Fuess, J. Bill and F. Aldinger, Angew. Chem., Int. Ed. Engl., 36, 603-606 (1997).

34) Y. L. Li, E. Kroke, A. Klonczynski and R. Riedel, Adv. Mater., 12, 956-961 (2000).

35) A. O. Gabriel and R. Riedel, Angew. Chem., Int. Ed. Engl., 36, 384-386 (1997).

36) H. D. Li, G. T. Zou, H. Wang, H. B. Yang, D. M. Li, M. H. Li, S. Yu, Y. Wu and Z. F. Meng, J. Phys. Chem. B, 102, 86928695 (1998).

37) K. Jagannadham, A. K. Sharma, Q. Wei, R. Kalyanraman and J. Narayan, J. Vac. Sci. Technol., A, 16, 2804-2815 (1998).

38) J. J. Fitzgerald, S. D. Kohl and G. Piedra, Chem. Mater., 6, 1915-1917 (1994).

39) W. S. Jung and S. K. Ahk, J. Mater. Sci. Lett., 16, 1573-1575 (1997). 